I7 ; and besides, the important observation of the disappearance of the comet at the sun's limb is very valuable. Now then, if it will be possible to secure some observations in the remaining days the comet will be visible, I am sure we shall have a large amount of material to study upon.

I may add that Mr. Common and I saw the comet a few days ago. With magnifying power of 120 and 150 we were not able to distinguish the division of the nucleus, but with a higher power we saw five bright points; one of these, corresponding to that seen before, remains the brightest. The comet has all the appearance of a little curve convex to the horizon, and is still a very bright object, as Mr. Common was able to see it pretty well with only six inches aperture and in moonlight.

I3, Pembridge Crescent, Bayswater, W.

E. RISTORI

\section{Aino Ethnology}

LET me basten to assure Herr Rein that nothing could have been further from my intention than to question the "love of truth," which is conspicuous in his work on Japan. I trust he will consider as absolutely withdrawn any expression of mine which he fancies might at all bear such a construction. $\mathrm{His}$ authorities I did not quote, because I attached much more importance to the weight of his name than to theirs. The almost unanimous opinion of original observers is opposed to their conclusions, which I was certainly somewhat surprised to find adopted by Herr Rein. But as he has not himself visited the Aino people, the question of their affinities need not be further argued here. I may state, however, that to Steube and von Siebold must now be added Herr Kreitner, of the Szechenyi expedition, who emphatically removes them from the Mongolic, and "assimilates them to the Caucasic type" ("Im Fernen Osten," Vienna, I881, p. 318).

A. H. Keane

\section{Auroral Experiments in Finland}

IN the note in NATURE, vol. xxvii. p. 322, in which you refer to my telegrams from Sodankylä, there is a misunderstanding concerning the apparatus which I made use of in the experiments. This apparatus, which I call in Swedish "Utfrömningo-apparat" (streaming apparatus), was constructed of uncovered copper wire, provided at each half-metre with fine erected points. That wire was led in slings to the top of the hill, and reposed on the usual telegraph insulators. From one end of this wire was conducted a covered copper wire on insulators to the foot of the hill ( 600 feet high), and there joined a plate of zinc interred in the earth. In this circuit was put a galvanometer.

It was this apparatus which produced both the yellow-white halo at Oratunturi and the straight beam of aurora borealis at Pietarintunturi, as the positive current in the galvanometer at both places. The terrestrial current diminishes (or ceases) below the belt of maxima of the aurora borealis. S. LEMSTRöM

Helsingfors

\section{Flamingoes and Cariamas}

In NATURE, vol. xxvii. p. 334, an accotnt is given of the curious behaviour of a flamingo towards a cariama. May I point out that this habit of the flamingo was observed in 1869 by Mr. Bartlett, and will be found in a P.S. to a paper of his entitled "Remarks upon the Habits of the Hornbills," read before the Zoological Society, February 25, 1869. The liquid was examined by Dr. Murie, and is said to have consisted almost entirely of blood. A short notice of the habit, communicated by Mr. Bartlett, appears also in Buckland's Edition of "White's Selborne."

Cambridge, February 19

\section{THE APPROACHING FISHERY EXHIBITION}

$\mathrm{F}$ ROM the cheerful note of preparation which is now being sounded, we presume the opening of the International Fisheries Exhibition will take place punctually on the day which has been fixed for that eventMay I. That the Exhibition will be successful, both in a pecuniary sense and as an exposition of fishery economy and of the natural history of our food fishes, may, we think, be even now predicted. The two exhibitions by which it has been preceded, those of Edinburgh and Norwich, not only paid all expenses, but left a handsome surplus; so that, with the vast population of London and the strangers who daily come within its gates to work upon, the promoters of the exposition are warranted in believing that it will prove a success. It will undoubtedly be the greatest affair of the sort which has yet been designed, and will occupy a site twice as large as the Norwich and Edinburgh exhibitions joined together. The fishery exhibition which was held at Berlin three years ago was visited by nearly half a million persons, but it was only open for ten weeks, whilst the show to be held at South Kensington will remain open for six months, and as the population of London is more than four times greater than that of Berlin, we may calculate on the visitors to the Fishery Exhibition running into big figures; - two million persons at a shilling each would represent a sum of one hundred thousand pounds. Already a large guarantee fund has been subscribed by corporations and private persons, and there is no reason why Parliament should not be asked for a grant in aid, although any money that might be granted may not be required. It is right to say that as a nation we play a rather "mean" part in such matters, and are quite outdone in liberality by other countries. America, for instance, is sending us an "exhibit" which will cost that country ten thousand pounds, and other foreign countries are acting in an equally liberal spirit. If we were asked on any occasion to reciprocate, what answer could we make? We have positively nothing that we could send. With the exception of the toy museum left to the country by Mr. Frank Buckland, we possess nothing in the shape of a national collection illustrative of fishery economy; hence the Exhibition which is about to open assumes very much the shape of a commercial enterprise, and becomes a gate-money show. But that is better than nothing, and it is to be hoped that from the debris of the approaching exposition a substantial addition may be made to the Buckland Museum of economic fish culture, and if we may be permitted to make such a suggestion, the aquarium should, if that is possible, be so arranged that it could be left as a permanent attraction for all who are interested in the natural history of fish and in the proper ingathering of the harvest of the sea.

Great expectations are entertained as to the value of the lessons to be taught at the approaching Exhibition. We are undoubtedly in need of knowledge of all kinds regarding the natural history of our fishes. From the whitebait to the whale we are singularly deficient in those details of fish life that would prove valuable to persons engaged in fishery enterprise. In the matter of well-planned investigation into the natural history of the British food fishes we are far behind America, where information of the most valuable kind is systematically collected and disseminated. As a matter of fact, we have (as a nation) done almost nothing in respect of adding to the knowledge of the public. Some individuals have been toying with the subject of Pisciculture, whilst in the seas that pertain to the United States fish-breeding on an extended scale has been long in operation under the auspices of the Government. It will not be the fault of the promoters of the approaching Exhibition if attention is not aroused to our want of interest (as a people) in the sea-fisheries of the country. We have therefore every reason to be grateful to those who have stepped to the front in order to promote this enterprise; the men who have assumed the lead have nothing to gain personally by its success - they are working in the interests of the public, knowing well that the fisheries of the surrounding coasts contribute largely to the commissariat of the country.

A portly prospectus, so far as its contents are concerned, has been issued, indicative of what will be shown in the Exposition, and from that document we gather that a large 
sum of money will be distributed in prizes for inventions and improvements of fishing gear; the special prizes in this department alone will number over Ioo, ranging in value from $600 l$. to $2 l$. IOs. Over $1000 l$. will also be given for essays on various topics connected with the economy of the fisheries and the natural history of our more important food fishes, as also for papers on fishery legislation. The dissemination of the knowledge to be obtained from such essays as may be awarded prizes is important. None of the essays contributed to the Norwich Exhibition have been published, except that of Sir James Maitland, printed presumably at his own expense, so that whatever information was contained in the Norwich prize essays remains only in the cognisance of those who read them. The Edinburgh prize essays are, we believe, being printed. Surely they might have been published ere this, and it might be taken into consideration by the executive of the present Exhibition, whether it is possible to have the essays judged, the prizes awarded, and a print of such as are worthy of being published on sale in the building in the course of the summer : a popular "handbook" to the Exposition will, we may presume, be issued. As to " exhibits" of a useful kind, such as those of fishing gear of every description, men with a practical turn of mind will be able to take stock of them and perceive at a glance how far they can be utilised. As a class, fishermen are slow to learn and chary in the way of trying experiments, but it is not impossible that the approaching Exhibition may contain the germs of some new ideas which may prove alike practical and profitable.

\section{THE PROGRESS OF TELEGRAPHY}

THE first of the series of six lectures on the Applications of Electricity was delivered on Thursday evening, February I 5, at the Institution of Civil Engineers, on "The Progress of Telegraphy," by Mr. W. H. Preece, F.R.S., M.Inst.C.E., of which the following is an abstract :-

Telegraphy is the oldest practical application of electricity. It grew about the railway system, and was rendered a practical agent by the foresight of Robert Stephenson, I. K. Brunel, Joseph Locke, and G. P. Bidder, who were its godfathers in England. Electric currents are, as a rule, maintained for telegraphic purposes by the combustion of zinc, and in the innumerable forms of batteries in use, the conversion of zinc into sulphate of zinc is the root of the transformation of energy into that form which was utilised as electric currents. There are three forms of battery in use in the British Post-Office Telegraph system, and in the following numbers :-

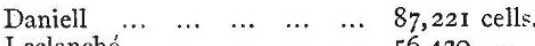

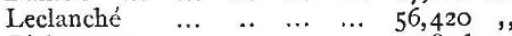

$$
\begin{aligned}
& \text { Bichromate } \quad \ldots \quad \ldots \quad \ldots \quad \ldots \quad 2 \mathrm{I}, 846 \text {, }
\end{aligned}
$$

Every administration has its own adopted form, differing in design, but based on one or other of these types. Magneto-electricity is employed for some forms of apparatus, and dynamo-machines are sometimes used to supplement batteries. Experiments are now being made with secondary ba'teries. The various terms employedelectromotive force, resistance, induction, and currentthough measurab'e in definite units, have not yet become household words; but, being admitted into commercial, legal, and Parliamentary lore, they will soon be as familiar as feet, gallons, or pounds.

Electric currents are conveyed from place to place either overground, underground, or submarine.

Ovenground.-Wooden poles preserved in creosote are employed in England, but iron poles are extensively used in the colonies. The conducting wire is almost universally of iron, but copper wire is much used through smoky places where iron is liable to rapid decay. Phosphor-bronze wire is under trial, and is a very promising material, as it possesses the conductivity of copper with the strength of iron. The improvements made in the quality of iron wire have been very great, and it conducts now fully 50 per cent. better than it did a few years ago. Electric tests have had a marvellous effect upon the production of pure metallic conductors; copper has improved in even greater ratio than iron; samples have been produced better even than the standard of purity. The insulators remain principally of porcelain, and their forms vary nearly with the number of individuals who use them; the only improvement of any value recently made is one which facilitates the very necessary process of cleaning.

Underground.--Wires are almost invariably carried underground through towns. Copper wire, insulated with gutta-percha, incased in iron pipes, is the material used. There are 12,000 miles of underground wire in the United Kingdom. There is a great outcry for more underground work in England, owing to the destruction to open lines by gales and snowstorms; but underground telegraphs, wire for wire, cost at present about four times as much as overground lines, and their capacity for the conveyance of messages is only one-fourth ; so that overground are, commercially, sixteen times better than underground wires. To lay the whole of the Post-Office system underground would mean an expenditure of about $20,000,000 l$. Hence there is no desire to put wires underground except in towns. Besides snowstorms are few and far between, and their effects are much exaggerated. of the numerous materials and compounds that have been used for insulating purposes, gutta-percha remains the oldest and the best for underground purposes. It, like all other materials used for telegraphy, has been improved vastly through the searching power that the current gives the engineer.

Submarine.-The past ten years has seen the globe covered with a network of cables. Submarine telegraphs have become a solid property. They are laid with facility and recovered with certainty, even in the deepest oceans. Thanks to such expeditions as that of H.M.S. Challenger, the floor of the ocean is becoming more familiar than the surface of many continents. There are at present 80,000 miles of cable at work, and $30,000,000 l$. have been embarked in their establishment. A fleet of twenty-nine ships is employed in laying, watching, and repairing the cables. The Atlantic is spanned by nine cables in working order. The type of cable used has been but very little varied from that first made and laid between Dover and Calais; but the character of the materials, the quality of the copper and the gutta-percha, the breaking strain of the homogeneous iron wire, which has reached go tons to the square inch, and the machinery for laying, have received such great advances, that the last cable laid across the Atlantic, by the Telegraph Construction and Maintenance Company, was done in twelve days without a hitch or stoppage.

Ideas are conveyed to the mind by electric signals, and in telegraphy these signals are produced at distant places by using two simple electrical effects: (I) that a magnetic needle tends to place itself at right angles to a wire when an electric current passes through it; and (2) that a piece of iron becomes a magnet when a current of electricity circulates around it. An innumerable quantity of tunes can be played on these two strings. Various companies were established at different times to work certain systems, but when the telegraphs were absorbed by the State the fittest were selected to survive, and their number consequently declined.

The A B C instrument is the simplest to read, for it indicates the letters of the alphabet by causing a pointer to dwell opposite the desired letter. There are 4398 in use. Its mechanism is, however, complicated and expensive, and it is being rapidly supplanted by the telephone. The needle instrument is the simplest in con- 